\title{
Performance Evaluation of Portfolios with Margin Requirements
}

\author{
Hui Ding, ${ }^{1}$ Zhongbao Zhou, ${ }^{1}$ Helu Xiao, ${ }^{1}$ Chaoqun Ma, ${ }^{1}$ and Wenbin Liu ${ }^{1,2}$ \\ ${ }^{1}$ School of Business Administration, Hunan University, Changsha 410082, China \\ ${ }^{2}$ Kent Business School, University of Kent, Canterbury CT2 7PE, UK \\ Correspondence should be addressed to Zhongbao Zhou; zhongbaozhou@gmail.com
}

Received 6 January 2014; Accepted 7 February 2014; Published 12 March 2014

Academic Editor: Fenghua Wen

Copyright (c) 2014 Hui Ding et al. This is an open access article distributed under the Creative Commons Attribution License, which permits unrestricted use, distribution, and reproduction in any medium, provided the original work is properly cited.

\begin{abstract}
In financial markets, short sellers will be required to post margin to cover possible losses in case the prices of the risky assets go up. Only a few studies focus on the optimization and performance evaluation of portfolios in the presence of margin requirements. In this paper, we investigate the theoretical foundation of DEA (data envelopment analysis) approach to evaluate the performance of portfolios with margin requirements from a different perspective. Under the mean-variance framework, we construct the optimization model and portfolio possibility set on considering margin requirements. The convexity of the portfolio possibility set is proved and the concept of efficiency in classical economics is extended to the portfolio case. The DEA models are then developed to evaluate the performance of portfolios with margin requirements. Through the simulations carried out in the end, we show that, with adequate portfolios, DEA can be used as an effective tool in computing the efficiencies of portfolios with margin requirements for the performance evaluation purpose. This study can be viewed as a justification of DEA into performance evaluation of portfolios with margin requirements.
\end{abstract}

\section{Introduction}

In financial markets, the potential losses on short sales can be huge when the prices of the risky assets go up; therefore, in practice, the short sellers will be required to post margin or collateral to cover possible losses. In practice, margin requirements were firstly developed in the Securities Act of 1933, the Banking Act of 1933, and the Securities Exchange Act of 1934.

Most studies on margin requirements focus on margin calculation, relationship among margin requirements and stock prices, market volatility, investor behaviors, and so forth. For example, Lintner [1] analyzes the effect of short selling and margin requirements in perfect capital markets and states that the escrowing requirements not only involve forced or "by-product" holdings of the (nominally) riskless asset but also change the structure of the investor's wealth constraint by requiring the substitution of absolute values for the natural number of shares when short sales are made. Schwert [2] argues that the increase in stock prices has been associated with a decrease in volatility and the changes in margin requirements may not reduce subsequent stock return volatility. Hardouvelis [3] finds that higher margin requirements are associated with lower stock price volatility, lower excess volatility, and smaller deviations of stock prices throughout the post-1934 period. Thus, he concludes that margin requirements seem to be an effective policy tool in curbing destabilizing speculation. Hsieh and Miller [4] state that Federal Reserve margin requirements would not have served to dampen stock market volatility. They detect the expected negative relation between margin requirements and the amount of margin credit outstanding and confirm the findings by Schwert [2] that changes in margin requirements have tended to follow rather than lead changes in market volatility. Seguin [5] studies the effectiveness of using margin as a policy tool by contrasting the volatility and trading volume of NASDAQ stocks surrounding the date when they were declared as margin-eligible by the Federal Reserve System during 1977-1987. He finds that volume increased, while volatility decreased once stocks became margin-eligible. Kupiec and Sharpe [6] adopt an overlapping generation model to characterize the effects of initial margin 
requirements on the volatility of risky asset prices. They show that imposing a binding initial margin requirement may either increase or decrease stock price volatility, depending on the microeconomic structure behind fluctuations. Seguin and Jarrell [7] compare the crash behavior of NASDAQ assets eligible for margin trading with the behavior of ineligible ones from the crash of 1987. They find that margin-eligible assets were more frequently subjected to margin calls and forced sales. Watanabe [8] examines the pattern of autocorrelation of daily stock index returns in the Tokyo Stock Exchange and finds that an increase in margin requirements makes stock returns more positively autocorrelated. Hirose et al. [9] examined the relationship between investor behavior and stock returns focusing on Japanese margin transactions from 1994 to 2003. They find a significant cross-sectional relationship between margin buying and stock returns at the firm level, and margin buying traders follow herding behavior at market and firm levels. They conclude that information about margin buying helps to predict future stock returns, especially for small-firm stocks at short horizons.

Portfolio optimization and performance evaluation, on the other hand, are also an important topic in financial studies. There are numerous researches on this point, such as Markowitz [10], Branda [11], Wen and Dai [12], Huang et al. [13], Wen et al. [14], Qin et al. [15], and Huang et al. [16]. However, only a few studies focus on this issue in the presence of margin requirements. Heath and Jarrow [17] examine the impact of margin requirements on consumption choices and the cost of hedging contingent claims. They claim that margin requirements are sufficient to rule out arbitrage opportunities and Black-Scholes formula should still correctly price a call option in equilibrium as long as the constraints imposed by margin requirements are never binding. Cuoco and Liu [18] examine the optimal consumption and investment choices by using martingale and duality techniques under general assumptions on the assets' price process and the investors' preferences. They find the explicit solutions for an agent with "logarithmic" utility and a PDE characterization of the cost of hedging a nonnegative path-independent European contingent claim. Liu and Longstaff [19] derive the optimal investment policy of a risk-averse investor in a market, where there is a textbook arbitrage opportunity, but where liabilities must be secured by margin. They find that it is often optimal to underinvest in the arbitrage by taking a smaller position than collateral constraints allow. Even when the optimal policy is followed, the arbitrage portfolio typically experiences losses before the final convergence date. Deng et al. [20] consider a situation where an investor must liquidate positions in a portfolio to meet the margin call with the least disruption to the portfolio. They obtain the first- and second-order analytic estimates for the margin requirements given the positions and determine the liquidation strategy that minimizes the total positions liquidated and meets the margin requirement. Zhou and $\mathrm{Wu}$ [21] consider the continuous-time mean-variance portfolio selection problem in the situation when investors must pay margin for short selling. They figure out the solutions of HJB equation in two disjoint regions and prove that it is the viscosity solution of $\mathrm{HJB}$ equation by decomposing the problem into several subproblems. Then, they formulate the solution of optimal portfolio and the efficient frontier.

In this work, we consider the situation where short selling is allowed and deposit of certain percentage margin according to the shorting is needed to avoid loss by default of short seller. In this situation, we examine the DEA (data envelopment analysis) approach, a nonparametric technique proposed by Charnes et al. [22], to evaluate the performance of portfolios. In fact, DEA approach has been introduced to benchmark the relative performance of portfolios, mutual funds more recently. For example, Murthi et al. [23] firstly propose a DEA model by taking into account the transaction costs and define the efficiency measure: DPEI. Basso and Funari [24] propose an indicator $I_{\mathrm{DEA}-1}$, which can be regarded as a generalization of the DPEI that allows consideration of different risk measures. They also propose the $I_{\mathrm{DEA}-2}$ measure to reflect investors' preference structures and occurrence time of return. Basso and Funari [25] further develop a comprehensive index $I_{\text {DEA-g }}$, which is derived by combining $I_{\text {DEA-2 }}$ with a few traditional performance indexes that can represent particular aspects of the link between risk and return. With the minimum convex input requirement set approach, Chang [26] proposed a nonstandard DEA formulation to evaluate the performance of mutual funds, in which the expected return is used as output and the standard deviation, beta, total assets, and loan are regarded as inputs. Joro and $\mathrm{Na}$ [27] develop a portfolio performance measure based on mean-variance-skewness framework by utilizing DEA. Lamb and Tee [28] explore the production possibility set of the investment funds to identify an appropriate form of returns to scale. They also discuss how to combine risk and return measures to identify suitable sets of measures. Lozano and Gutiérrez [29] combine DEA with stochastic dominance criteria and propose six distinct DEA-like linear programming (LP) models for computing relative efficiency scores consistent (in the sense of necessity) with secondorder stochastic dominance (SSD). Branda [11] dealt with diversification-consistent DEA tests suitable for accessing financial efficiency of investment opportunities and derived a linear programming formulation of the tests with $\mathrm{CVaR}$ deviations. However, most of the above studies focus on the choice of input and output indicators and they use the trading data directly without considering the truth behind. In fact, there are many cases that trading data are generated where short selling is allowed and margin requirements are needed. In this work, we will further clarify these important issues and investigate the theoretical foundation of DEA approach for portfolios with margin requirements for short selling.

This paper is organized as follows. In Section 2, we construct the portfolio optimization models with margin requirements under the mean-variance framework. We prove that the corresponding portfolio possibility set is convex, which is the theoretical foundation for using DEA to evaluate the performance of portfolios with margin requirements. In Section 3, we define the efficiency of portfolio with margin requirements based on the exact frontiers. Then, we construct the DEA models to evaluate the efficiencies of portfolios with margin requirements. In Section 4, we carry out simulations for the portfolio optimization and DEA models. Results show 
that the DEA frontiers can be used to approximate the exact frontiers. Section 5 concludes the paper.

\section{Portfolios Optimization with Margin Requirements under Mean-Variance Framework}

2.1. Portfolio Optimization Models with Margin Requirements. Consider the problem of selecting a portfolio from $n$ financial assets. Assets are characterized by an expected return $E\left(R_{i}\right)$, for $i \in\{1, \ldots, n\}$, and a covariance matrix $G=\left(\sigma_{i j}\right)_{n \times n}=$ $\operatorname{cov}\left(R_{i}, R_{j}\right)$, for $i, j \in\{1, \ldots, n\}$, where $R_{i}$ is a random variable to represent the return of financial asset $i$. A portfolio $x=$ $\left(x_{1}, \ldots, x_{n}\right)^{T}$ is composed of a proportion of each of these $n$ financial assets. When short selling is excluded for financial asset $i$, the condition $x_{i} \geq 0$ is imposed.

In real investment, short selling is sometimes relevant for mutual funds, and even more for hedge funds. At the same time, in order to reduce the potential losses in case of default, short sellers are obliged to deposit and maintain a minimum amount of cash or discounted risky assets (margin requirements) with their broker-dealer. In particular, initial margin requirements set the minimum margin deposit, with which a position can be opened, and maintenance requirements set a floor, below which the margin deposit is not allowed to fall as long as the position remains open. Under Regulation $T$, the Federal Reserve Board requires all short sale accounts to have $150 \%$ of the value of the short sale at the time the sale is initiated. The $150 \%$ consists of the full value of the short sale proceeds (100\%), plus an additional margin requirement of $50 \%$ of the value of the short sale. For example, if an investor initiates a short sale for 1,000 shares at $\$ 10$, the value of the short sale is $\$ 10,000$. The initial margin requirement is the proceeds $\$ 10,000(100 \%)$, along with an additional $\$ 5,000(50 \%)$, for a total of $\$ 15,000$.

For simplicity, we do not distinguish the initial margin and maintenance margin in this work. We denote by $\beta_{i} \geq$ 1 the margin requirement level on short position for risky asset $i$, where $i \in\{1, \ldots, n\}$. In order to meet the margin requirement, investors can use cash or discounted long positions. We denote by $0 \leq \alpha_{i} \leq 1$ the discount rate of the value of long position for the owned risky asset $i \in\{1, \ldots, n\}$. Then, the margin requirements are imposed in the following constraints on an admissible portfolio:

$$
1-\sum_{i=1}^{n} x_{i}+\sum_{i=1}^{n} \alpha_{i} x_{i}^{+} \geq \sum_{i=1}^{n} \beta_{i} x_{i}^{-},
$$

where $x_{i}^{+}=\max \left\{0, x_{i}\right\}$ denotes the positive part of the real number $x_{i}$ and $x_{i}^{-}=-\min \left\{0, x_{i}\right\}$ the negative part. The above constraint states that the investor must hold an amount of cash and discounted risky assets in excess of the required margin.

If all margins are required to be cash, no discounted risky assets are allowed; then, we can set $\alpha_{i}=0$, for all $i \in\{1, \ldots, n\}$; the above constraint will degenerate to

$$
1-\sum_{i=1}^{n} x_{i} \geq \sum_{i=1}^{n} \beta_{i} x_{i}^{-} .
$$

We assume that the investors are allowed to lend and to borrow the cash at the same interest rate $r$. Then, the expected return of a portfolio $x=\left(x_{1}, \ldots, x_{n}\right)$ can be expressed as

$$
\sum_{i=1}^{n} x_{i} E\left(R_{i}\right)+\left(1-\sum_{i=1}^{n} x_{i}\right) r=\sum_{i=1}^{n} x_{i}\left(E\left(R_{i}\right)-r\right)+r .
$$

Thus, we can construct the following optimization model under the mean-variance framework proposed by Markowitz [10], which minimizes the variance of the portfolio subject to the constraints that the expected value is no less than the given level and the margin requirements are satisfied. Consider

$$
\begin{array}{ll}
\min & \sum_{i=1}^{n} \sum_{j=1}^{n} x_{i} \sigma_{i j} x_{j} \\
\text { s.t. } & \sum_{i=1}^{n} x_{i}\left(E\left(R_{i}\right)-r\right)+r \geq r_{0} \\
& 1-\sum_{i=1}^{n} x_{i}+\sum_{i=1}^{n} \alpha_{i} x_{i}^{+} \geq \sum_{i=1}^{n} \beta_{i} x_{i}^{-},
\end{array}
$$

where $r_{0} \geq 0$ is a predetermined level by the investor. With the change of $r_{0}$, we can formulate the exact frontier of portfolios with margin requirements.

Accordingly, we can develop the following optimization model, which maximize the expected value subject to the constraints that the variance of the portfolio is no greater than the given level and the margin requirements are satisfied. Consider

$$
\begin{array}{ll}
\max & \sum_{i=1}^{n} x_{i}\left(E\left(R_{i}\right)-r\right)+r \\
\text { s.t. } & \sum_{i=1}^{n} \sum_{j=1}^{n} x_{i} \sigma_{i j} x_{j} \leq \sigma_{0} \\
& 1-\sum_{i=1}^{n} x_{i}+\sum_{i=1}^{n} \alpha_{i} x_{i}^{+} \geq \sum_{i=1}^{n} \beta_{i} x_{i}^{-},
\end{array}
$$

where $\sigma_{0} \geq 0$ is a predetermined level by the investor. With the change of $\sigma_{0}$, we can obtain the exact frontier of portfolios with margin requirements.

If we can set $\alpha_{i}=0$, for all $i \in\{1, \ldots, n\}$, then the models (4) and (5) will degenerate to the case that only cash margin is allowed.

2.2. Portfolio Possibility Set and Its Convexity. For the purpose of using DEA to evaluate the performance of portfolios with margin requirements, we must construct the theoretical foundation, that is, the convexity of the following portfolio possibility set with the strongly free disposability principle proposed by Liu et al. [30], in the presence of margin requirements. Consider

$$
P=\left\{(V, E) \in R_{+}^{2} \mid \exists x, V \geq \sum_{i=1}^{n} \sum_{j=1}^{n} x_{i} \sigma_{i j} x_{j},\right.
$$




$$
\left.\begin{array}{l}
E \leq \sum_{i=1}^{n} x_{i}\left(E\left(R_{i}\right)-r\right)+r, \\
1-\sum_{i=1}^{n} x_{i}+\sum_{i=1}^{n} \alpha_{i} x_{i}^{+} \geq \sum_{i=1}^{n} \beta_{i} x_{i}^{-}
\end{array}\right\} .
$$

Note that model (4) and model (5) will lead to the same portfolio possibility set (6). Thus, we will prove that this set is convex.

Theorem 1. The portfolio possibility set in (6) is convex.

Proof. Let $\Omega=\left\{x \mid 1-\sum_{i=1}^{n} x_{i}+\sum_{i=1}^{n} \alpha_{i} x_{i}^{+} \geq \sum_{i=1}^{n} \beta_{i} x_{i}^{-}\right\}$, $f(x)=\sum_{i=1}^{n} x_{i}\left(E\left(R_{i}\right)-r\right)+r$, and $g(x)=\sum_{i=1}^{n} \sum_{j=1}^{n} x_{i} \sigma_{i j} x_{j}$, where $x^{+}=\max \{0, x\}$ and $x^{-}=-\min \{0, x\}$. Then, the portfolio possibility set (5) can be rewritten as

$$
P=\left\{(V, E) \in R_{+}^{2} \mid V \geq g(x), E \leq f(x), x \in \Omega\right\} .
$$

For any $\left(V_{1}, E_{1}\right),\left(V_{2}, E_{2}\right) \in P$, there exist $x^{1}, x^{2} \in \Omega$ satisfying

$$
\begin{aligned}
f\left(x^{1}\right) \geq E_{1}, \quad & g\left(x^{1}\right) \leq V_{1}, \quad f\left(x^{2}\right) \geq E_{2}, \\
g\left(x^{2}\right) & \leq V_{2} .
\end{aligned}
$$

Since $x^{1}, x^{2} \in \Omega$, we have

$$
\begin{aligned}
& \sum_{i=1}^{n} x_{i}^{1}-\sum_{i=1}^{n} \alpha_{i} x_{i}^{1+}+\sum_{i=1}^{n} \beta_{i} x_{i}^{1-} \leq 1, \\
& \sum_{i=1}^{n} x_{i}^{2}-\sum_{i=1}^{n} \alpha_{i} x_{i}^{2+}+\sum_{i=1}^{n} \beta_{i} x_{i}^{2-} \leq 1 .
\end{aligned}
$$

For any $\lambda \in[0,1]$, notice that $0 \leq \alpha_{i} \leq 1$ and $\beta_{i} \geq 1$; we have

$$
\begin{aligned}
\sum_{i=1}^{n}[ & \left.\lambda x_{i}^{1}+(1-\lambda) x_{i}^{2}\right]-\sum_{i=1}^{n} \alpha_{i}\left[\lambda x_{i}^{1}+(1-\lambda) x_{i}^{2}\right]^{+} \\
& +\sum_{i=1}^{n} \beta_{i}\left[\lambda x_{i}^{1}+(1-\lambda) x_{i}^{2}\right]^{-} \\
= & \sum_{i=1}^{n}\left[\lambda x_{i}^{1}+(1-\lambda) x_{i}^{2}\right]^{+}-\sum_{i=1}^{n}\left[\lambda x_{i}^{1}+(1-\lambda) x_{i}^{2}\right]^{-} \\
& -\sum_{i=1}^{n} \alpha_{i}\left[\lambda x_{i}^{1}+(1-\lambda) x_{i}^{2}\right]^{+}+\sum_{i=1}^{n} \beta_{i}\left[\lambda x_{i}^{1}+(1-\lambda) x_{i}^{2}\right]^{-} \\
= & \sum_{i=1}^{n}\left(1-\alpha_{i}\right)\left[\lambda x_{i}^{1}+(1-\lambda) x_{i}^{2}\right]^{+} \\
& +\sum_{i=1}^{n}\left(\beta_{i}-1\right)\left[\lambda x_{i}^{1}+(1-\lambda) x_{i}^{2}\right]^{-} \\
\leq & \sum_{i=1}^{n}\left(1-\alpha_{i}\right)\left[\lambda x_{i}^{1+}+(1-\lambda) x_{i}^{2+}\right] \\
& +\sum_{i=1}^{n}\left(\beta_{i}-1\right)\left[\lambda x_{i}^{1-}+(1-\lambda) x_{i}^{2-}\right]
\end{aligned}
$$

$$
\begin{aligned}
= & \lambda\left(\sum_{i=1}^{n} x_{i}^{1}-\sum_{i=1}^{n} \alpha_{i} x_{i}^{1+}+\sum_{i=1}^{n} \beta_{i} x_{i}^{1-}\right) \\
& +(1-\lambda)\left(\sum_{i=1}^{n} x_{i}^{2}-\sum_{i=1}^{n} \alpha_{i} x_{i}^{2+}+\sum_{i=1}^{n} \beta_{i} x_{i}^{2-}\right) \leq 1 .
\end{aligned}
$$

Thus, $\Omega$ is a convex set, and

$$
\lambda x^{1}+(1-\lambda) x^{2} \in \Omega
$$

Note that $f(x)$ is a concave function; we have

$$
\begin{aligned}
f\left(\lambda x^{1}+(1-\lambda) x^{2}\right) & \geq \lambda f\left(x^{1}\right)+(1-\lambda) f\left(x^{2}\right) \\
& \geq \lambda E_{1}+(1-\lambda) E_{2} .
\end{aligned}
$$

Since $g(x)$ is a convex function, we have

$$
\begin{aligned}
g\left(\lambda x^{1}+(1-\lambda) x^{2}\right) & \leq \lambda g\left(x^{1}\right)+(1-\lambda) g\left(x^{2}\right) \\
& \leq \lambda V_{1}+(1-\lambda) V_{2} .
\end{aligned}
$$

Thus,

$$
\begin{aligned}
& \lambda\left(E_{1}, V_{1}\right)+(1-\lambda)\left(E_{2}, V_{2}\right) \\
& \quad=\left(\lambda E_{1}+(1-\lambda) E_{2}, \lambda V_{1}+(1-\lambda) V_{2}\right) \in P .
\end{aligned}
$$

Therefore, $P$ is a convex set.

It is evident that the frontier functions determined by models (5) and (6) can be expressed as $\varphi(V)=\sup \{E$ । $(V, E) \in P\}$ and $h(E)=\inf \{V \mid(V, E) \in P\}$, respectively. Evidently, we can obtain the following corollaries.

Corollary 2. The frontier $E=\varphi(V)$ determined by model (5) is a concave function.

Corollary 3. The frontier $V=h(E)$ determined by model (4) is a convex function.

By using the data in Section 4, two kinds of frontiers are computed: cash and discounted risky assets and only cash for margin requirements, as shown in Figure 1. As we can see, if cash and discounted risky assets are both allowed for margin requirements, the corresponding frontier is higher than the case that only cash is allowed for margin requirements. Moreover, it is obvious that the frontiers are not straight lines, which indicate that variable return to scale (VRS) should be adopted in the following DEA models; see detailed discussion in Banker et al. [31].

\section{Performance Evaluation of Portfolios with Margin Requirements}

3.1. Efficiencies for Portfolios with Margin Requirements. In classical economics, performance is often evaluated by efficiency. Farrell [32] defined efficiency as the ratio of the minimum inputs and actual inputs of producing a certain amount 


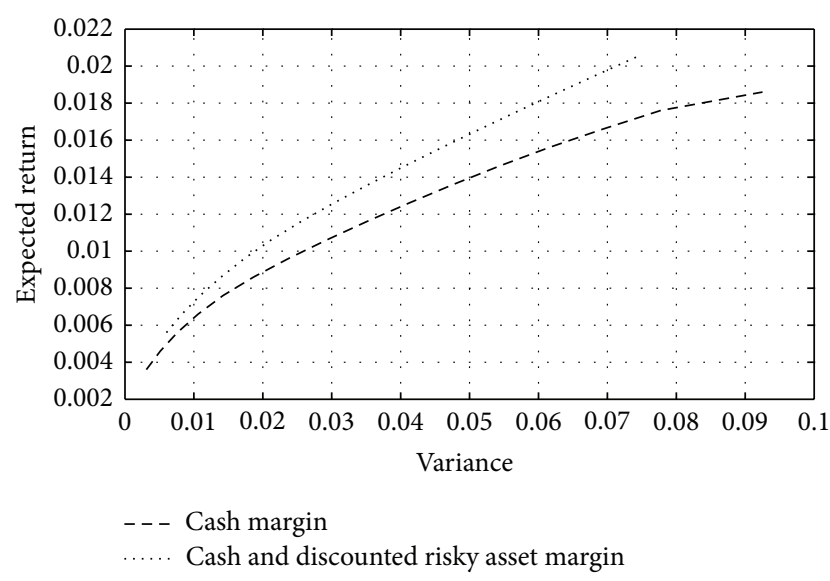

FIGURE 1: Exact frontiers of portfolios with different margin requirements.

of products in accordance with the given proportion of inputs. Leibenstein [33] defined that the efficiency is the ratio of the actual outputs and the maximum outputs with the same inputs scale, inputs proportion, and market price. These definitions are closely related to the production frontier, which theoretically represents the best level of a given production possibility set. Efficiency can be treated as the closeness of actual production activities of the production unit to the production frontier, and it reflects the production unit's relative efficiency. From the inputs viewpoint, it can be measured as a proportion of ideal inputs and actual inputs with the same outputs. From the output perspective, it can be measured as a proportion of production unit's actual outputs and ideal outputs by consuming the same inputs. Actual efficiency scores are quite related with the orientation and measurement methods to be adopted. As the one-input one-output example shown in Figure 2, X-axis represents inputs, Y-axis represents outputs, and curve $B_{1} B_{2}$ is the production frontier. Let $A$ be an actual production unit (located in the lower right side of the frontier). The efficiency can be defined as follows:

$$
\text { input-oriented radial measure: } \mathrm{TE}_{I}^{R}=A_{2} B_{2} / A_{2} A \text {, }
$$$$
\text { output-oriented radial measure: } \mathrm{TE}_{O}^{R}=A_{1} A / A_{1} B_{1} \text {. }
$$

In order to define the efficiency of portfolio under the mean-variance framework, the portfolio frontier can be regarded as the production frontier and the portfolio possibility set is in nature the production possibility set in classical economics. And the performance of a portfolio can be measured via its closeness to the frontier. According to the extended strongly free disposability discipline of Liu et al. [34], we treat variance as input and the expected return as output. Then, we can measure its closeness to the frontier by using the above efficiency measures to represent the performance of portfolios.

Since we have proved that the portfolio possibility set in (6) is convex, we can conclude that the frontiers derived by DEA models will approximate the exact frontier for portfolios with margin requirements due to the convergence theory in Banker et al. [31]. Therefore, we can use the efficiency

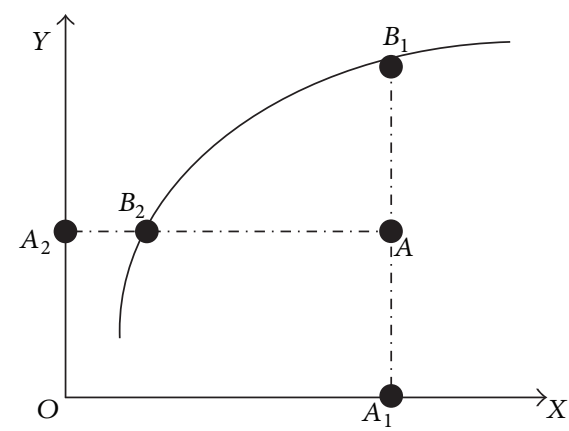

FIgURE 2: Efficiencies with different orientations.

scores of linear DEA models to estimate the efficiencies of portfolios with margin requirements. Moreover, DEA method is a nonparametric method based on actual data that naturally reflects different kinds of margin requirements on the markets.

3.2. DEA Models for Portfolios with Margin Requirements. DEA is a nonparametric approach based on the inputsoutputs analysis. It has been widely used to evaluate the performance of profit and nonprofit organizations [35-39]. There are many kinds of DEA models, for example, CCR model [22], BCC model [31], SBM model [40], and so forth. According to the characteristics of the frontier shown in Figure 1, we should adopt the assumption of variable return to scale for portfolios with margin requirements, as discussed in Section 2.2.

Suppose that there are $N$ portfolios with margin requirements. For the $j$ th portfolio, the proportion of risky assets is $\left(x_{1}^{j}, \ldots x_{n}^{j}\right)$. We can construct the following input-oriented DEA model by using radial measure to evaluate the performance of the $j_{0}$ th portfolio:

$$
\begin{array}{ll}
\min & \theta_{j 0} \\
\text { s.t. } & \sum_{j=1}^{N} \lambda_{j}\left(\sum_{i=1}^{n} \sum_{l=1}^{n} x_{i}^{j} \sigma_{i l} x_{l}^{j}\right) \leq \theta_{j 0}\left(\sum_{i=1}^{n} \sum_{l=1}^{n} x_{i}^{j 0} \sigma_{i l} x_{l}^{j 0}\right) \\
& \sum_{j=1}^{N} \lambda_{j}\left(\sum_{l=1}^{n} x_{i}^{j}\left(E\left(R_{i}\right)-r\right)\right) \geq \sum_{l=1}^{n} x_{i}^{j 0}\left(E\left(R_{i}\right)-r\right) \\
& \sum_{j=1}^{N} \lambda_{j}=1 \\
& \lambda_{j} \geq 0, \quad j=1, \ldots, N .
\end{array}
$$

Similarly, we can construct the following output-oriented DEA model:

$$
\begin{array}{ll}
\max & \varphi_{j 0} \\
\text { s.t } & \sum_{j=1}^{N} \lambda_{j}\left(\sum_{i=1}^{n} \sum_{l=1}^{n} x_{i}^{j} \sigma_{i l} x_{l}^{j}\right) \leq \sum_{i=1}^{n} \sum_{l=1}^{n} x_{i}^{j 0} \sigma_{i l} x_{l}^{j 0}
\end{array}
$$




$$
\begin{aligned}
& \sum_{j=1}^{N} \lambda_{j}\left(\sum_{l=1}^{n} x_{i}^{j}\left(E\left(R_{i}\right)-r\right)\right) \\
& \quad \geq \varphi_{j 0} \sum_{l=1}^{n} x_{i}^{j 0}\left(E\left(R_{i}\right)-r\right) \\
& \sum_{j=1}^{N} \lambda_{j}=1 \\
& \lambda_{j} \geq 0, \quad j=1, \ldots, N .
\end{aligned}
$$

The $j_{0}$ th portfolio is said to be BCC-efficient, if the optimal value is equal to unit in model (15) or model (16).

Basically, the DEA frontiers will approximate the exact frontier of portfolios with margin requirements. When there exist sufficient portfolios, the efficiency scores of DEA models will be close to the real efficiencies of portfolios. Thus, there is a quite reasonable conclusion: to make DEA work, there have to be enough portfolios. The advantage of this approach is that there is no need to know the analytical expression of the exact frontier, so that one can handle variety of complex situations. Moreover, since DEA models are linear programming models, they will reduce the computation dramatically.

\section{Simulation}

In this section, we will verify the validity of the above models with simulation. We select 150 stocks from the Chinese stock market. These monthly data are from January 2005 to January 2008. The descriptive statistics is listed in Table 1. Margin requirement levels are set to be $150 \%$ of the value of the short sale for all stocks. The discount rates for all stocks are set to be $40 \%$. Investors are allowed to loan or borrow cash at the same monthly interest rate $0.06 \%$.

The exact frontiers with cash margin, cash, and discounted risky asset margin are shown in Figure 1 in Section 2.2. As we can see that the frontier with cash and discounted risky asset margin is higher than that with cash margin and the corresponding portfolio possibility set is much larger, which coincide with the constraints of margin in the optimization models (4) and (5).

We then randomly generate proportions of risky assets to construct portfolio samples with margin requirements. The sample sizes are set to be $100,500,1000$, and 2000, respectively. The top curve in Figure 3 is the exact frontier calculated from model (4) by setting $\alpha_{i}=0$, for all $i \in\{1, \ldots, n\}$, which represents the case that only cash margin is allowed. The four polylines are the envelopment frontiers constructed by the proposed DEA model (15) with different sample sizes, respectively. As we can see, with the increasing of sample size, the frontiers of DEA models gradually approximate the exact frontier.

The top curve in Figure 4 is the exact frontier calculated from model (4), which represents the case that both cash and discounted risky asset margin are allowed. The four polylines in Figure 4 are the envelopment frontiers constructed by

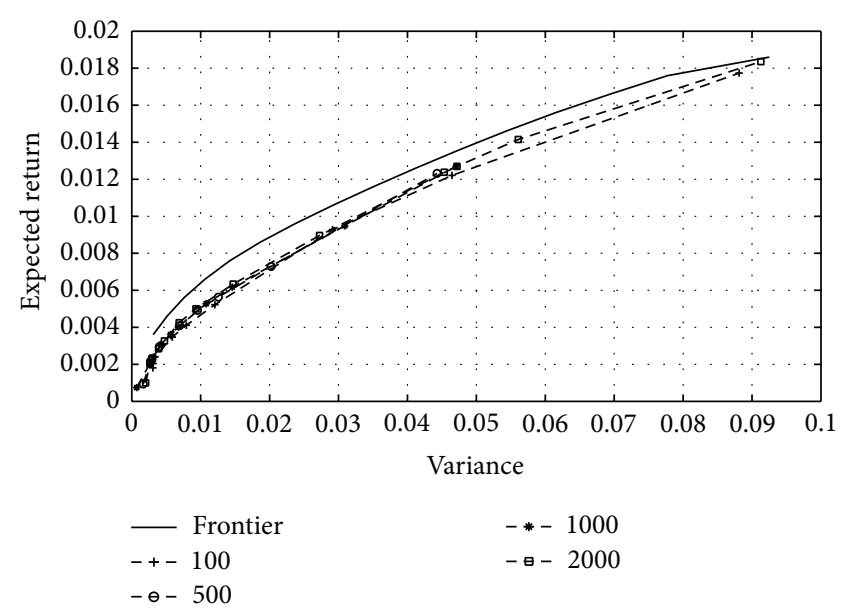

FIgure 3: Comparison of DEA frontiers with cash margin.

TABle 1: Descriptive statistics of selected stocks.

\begin{tabular}{lcccc}
\hline & Maximum & Minimum & Median & Mean \\
\hline Expected return & 0.0186 & 0.0007 & 0.0086 & 0.0087 \\
Variance & 0.0113 & 0.0028 & 0.0072 & 0.0072 \\
Covariance & 0.0113 & 0.0005 & 0.0040 & 0.0038 \\
\hline
\end{tabular}

TABLE 2: Correlation of efficiencies with different sample sizes and margin requirements.

\begin{tabular}{lcccc}
\hline Sample size & 100 & 500 & 1000 & 2000 \\
\hline $\begin{array}{l}\text { Cash margin } \\
\begin{array}{l}\text { Cash and discounted } \\
\text { risky asset margin }\end{array}\end{array}$ & 0.8778 & 0.9816 & 0.9818 & 0.9994 \\
\hline
\end{tabular}

the proposed DEA model (15) with sample sizes 100, 500, 1000 , and 2000, respectively. As we can see, with the increasing of sample size, the frontiers of DEA models gradually approximate the exact frontier.

Table 2 reports the correlations of the efficiencies calculated by the exact portfolio frontiers and DEA model with different margin requirements and sample sizes. We can see that the correlations increase with the sample size. It is also clear that, with a sample size of 500, reasonable approximation of efficiencies can be achieved, indicating the effectiveness of the proposed DEA approach.

\section{Conclusion}

In this work, we consider the situation that short selling is allowed and margin is required to avoid losses by default of short seller. Only a few studies focus on the optimization and performance evaluation of portfolios in this situation. This paper constructs the optimization model for portfolios with margin requirements and the corresponding portfolio possibility set. The convexity of the set is then proved, to ensure that the DEA frontier can approximate the exact frontier. The concept of efficiency in classical economics is extended to represent the performance of portfolios 


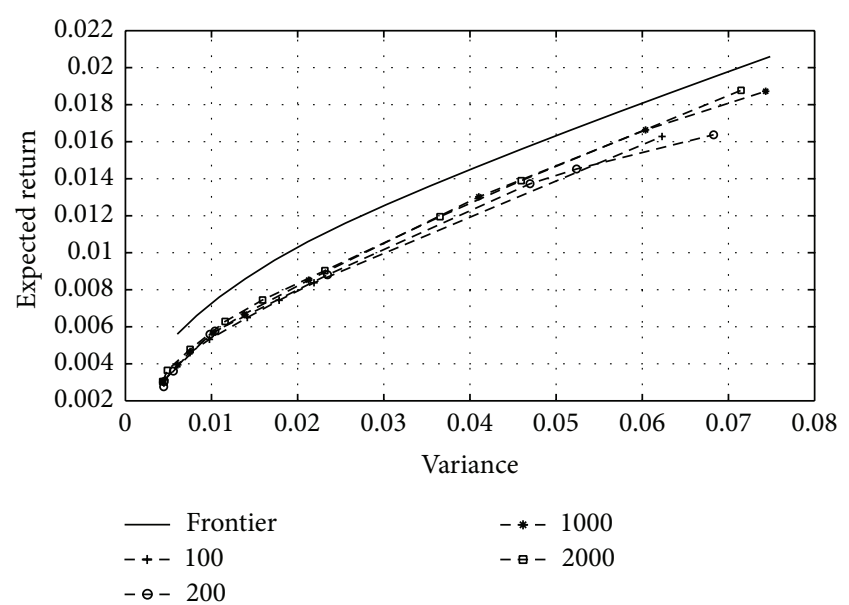

FIGURE 4: Comparison of DEA frontiers with cash and discounted risky asset margin.

with margin requirements. The input-oriented and outputoriented DEA models are constructed, which greatly simplify the calculation. Finally, the simulation example shows that, with the increase in sample size, DEA frontier gradually approximates the exact frontier of portfolios with margin requirements, which illustrates the feasibility and effectiveness of the proposed approach.

\section{Conflict of Interests}

The authors declare that there is no conflict of interests regarding the publication of this paper.

\section{Acknowledgment}

The research is supported by the Chinese National Natural Science Foundation (no. 71371067 and no. 70901024).

\section{References}

[1] J. Lintner, "The effect of short selling and margin requirements in perfect capital markets," Journal of Financial and Quantitative Analysis, vol. 6, no. 5, pp. 1173-1195, 1971.

[2] G. W. Schwert, "Margin requirements and stock volatility," Journal of Financial Services Research, vol. 3, no. 2-3, pp. 153$164,1989$.

[3] G. A. Hardouvelis, "Margin requirements, volatility, and the transitory component of stock prices," The American Economic Review, vol. 80, no. 4, pp. 736-762, 1990.

[4] D. A. Hsieh and M. H. Miller, "Margin regulation and stock market volatility," The Journal of Finance, vol. 45, no. 1, pp. 329, 1990.

[5] P. J. Seguin, "Stock volatility and margin trading," Journal of Monetary Economics, vol. 26, no. 1, pp. 101-121, 1990.

[6] P. H. Kupiec and S. A. Sharpe, "Animal spirits, margin requirements, and stock price volatility," The Journal of Finance, vol. 46, no. 2, pp. 717-731, 1991.

[7] P. J. Seguin and G. A. Jarrell, "The irrelevance of margin: evidence from the crash of '87," The Journal of Finance, vol. 48, no. 4, pp. 1457-1473, 1993.
[8] T. Watanabe, "Margin requirements, positive feedback trading, and stock return autocorrelations: the case of Japan," Applied Financial Economics, vol. 12, no. 6, pp. 395-403, 2002.

[9] T. Hirose, H. K. Kato, and M. Bremer, "Can margin traders predict future stock returns in Japan?" Pacific Basin Finance Journal, vol. 17, no. 1, pp. 41-57, 2009.

[10] H. Markowitz, "Portfolio selection," Journal of Finance, vol. 7, pp. 77-91, 1952.

[11] M. Branda, "Reformulations of input-output oriented DEA tests with diversification," Operations Research Letters, vol. 41, no. 5, pp. 516-520, 2013.

[12] F. Wen and Z. Dai, "Modified Yabe-Takano nonlinear conjugate gradient method," Pacific Journal of Optimization, vol. 8, no. 2, pp. 347-360, 2012.

[13] C. Huang, H. Kuang, X. Chen, and F. Wen, "An LMI approach for dynamics of switched cellular neural networks with mixed delays," Abstract and Applied Analysis, vol. 2013, Article ID 870486, 8 pages, 2013.

[14] F. Wen, Z. Li, C. Xie, and D. Shaw, "Study on the fractal and chaotic features of the Shanghai composite index," FractalsComplex Geometry Patterns and Scaling in Nature and Society, vol. 20, no. 2, pp. 133-140, 2012.

[15] G. Qin, C. Huang, Y. Xie, and F. Wen, "Asymptotic behavior for third-order quasi-linear differential equations," Advances in Differential Equations, vol. 2013, article 305, 2013.

[16] C. Huang, G. Xu, X. Chen, and F. Wen, "Measuring and forecasting volatility in Chinese stock market using HAR-CJM model," Abstract and Applied Analysis, vol. 2013, Article ID 143194, 13 pages, 2013.

[17] D. C. Heath and R. A. Jarrow, "Arbitrage, continuous trading, and margin requirements," The Journal of Finance, vol. 42, no. 5, pp. 1129-1142, 1987.

[18] D. Cuoco and H. Liu, "A martingale characterization of consumption choices and hedging costs with margin requirements," Mathematical Finance, vol. 10, no. 3, pp. 355-385, 2000.

[19] J. Liu and F. A. Longstaff, "Losing money on arbitrage: optimal dynamic portfolio choice in markets with arbitrage opportunities," Review of Financial Studies, vol. 17, no. 3, pp. 611-641, 2004.

[20] G. Deng, T. Dulaney, and C. McCann, "Optimizing Portfolio Liquidation under risk-based margin requirements," Journal of Finance and Investment Analysis, vol. 2, no. 1, pp. 121-153, 2013.

[21] Y. Zhou and Z. Wu, "Mean-variance portfolio selection with margin requirements," Journal of Mathematics, vol. 2013, Article ID 726297, 9 pages, 2013.

[22] A. Charnes, W. W. Cooper, and E. Rhodes, "Measuring the efficiency of decision making units," European Journal of Operational Research, vol. 2, no. 6, pp. 429-444, 1978.

[23] B. P. S. Murthi, Y. K. Choi, and P. Desai, "Efficiency of mutual funds and portfolio performance measurement: a non-parametric approach," European Journal of Operational Research, vol. 98, no. 2, pp. 408-418, 1997.

[24] A. Basso and S. Funari, "A data envelopment analysis approach to measure the mutual fund performance," European Journal of Operational Research, vol. 135, no. 3, pp. 477-492, 2001.

[25] A. Basso and S. Funari, "A generalized performance attribution technique for mutual funds," University of Venice Working Paper, vol. 8, no. 2, pp. 10-28, 2001.

[26] K.-P. Chang, "Evaluating mutual fund performance: an application of minimum convex input requirement set approach," Computers and Operations Research, vol. 31, no. 6, pp. 929-940, 2004. 
[27] T. Joro and P. Na, "Portfolio performance evaluation in a meanvariance-skewness framework," European Journal of Operational Research, vol. 175, no. 1, pp. 446-461, 2006.

[28] J. D. Lamb and K.-H. Tee, "Data envelopment analysis models of investment funds," European Journal of Operational Research, vol. 216, no. 3, pp. 687-696, 2012.

[29] S. Lozano and E. Gutiérrez, "Data envelopment analysis of mutual funds based on second-order stochastic dominance," European Journal of Operational Research, vol. 189, no. 1, pp. 230-244, 2008.

[30] W. Liu, J. Sharp, and Z. Wu, "Preference, production and performance in data envelopment analysis," Annals of Operations Research, vol. 145, no. 1, pp. 105-127, 2006.

[31] R. D. Banker, A. Charnes, and W. W. Cooper, "Some models for estimating technical and scale efficiencies in data envelopment analysis," Management Science, vol. 30, no. 9, pp. 1078-1092, 1984.

[32] M. J. Farrell, “The measurement of production efficiency," Journal of Royal Statistical Society A, vol. 120, no. 3, pp. 253-290, 1957.

[33] H. Leibenstein, "Allocative efficiency vs 'X-efficiency"' American Economic Review, vol. 56, pp. 392-415, 1966.

[34] W. B. Liu, W. Meng, X. X. Li, and D. Q. Zhang, "DEA models with undesirable inputs and outputs," Annals of Operations Research, vol. 173, no. 1, pp. 177-194, 2010.

[35] Z. Zhou, S. Lui, C. Ma, D. Liu, and W. Liu, "Fuzzy data envelopment analysis models with assurance regions: a note," Expert Systems with Applications, vol. 39, no. 2, pp. 2227-2231, 2012.

[36] Z. Zhou, L. Sun, W. Yang, W. Liu, and C. Ma, "A bargaining game model for efficiency decomposition in the centralized model of two-stage systems," Computers \& Industrial Engineering, vol. 64, no. 1, pp. 103-108, 2013.

[37] Z. Zhou, M. Wang, H. Ding, C. Ma, and W. Liu, "Further study of production possibility set and performance evaluation model in supply chain DEA," Annals of Operations Research, vol. 206, no. 1, pp. 585-592, 2013.

[38] Z. Zhou, W. Yang, C. Ma, and W. Liu, "A comment on "A comment on 'A fuzzy DEA/AR approach to the selection of flexible manufacturing systems" and 'A fuzzy DEA/AR approach to the selection of flexible manufacturing systems,' Computers \& Industrial Engineering, vol. 59, no. 4, pp. 1019-1021, 2010.

[39] Z. Zhou, L. Zhao, S. Lui, and C. Ma, "A generalized fuzzy DEA/AR performance assessment model," Mathematical and Computer Modelling, vol. 55, no. 11-12, pp. 2117-2128, 2012.

[40] K. Tone, "Slacks-based measure of efficiency in data envelopment analysis," European Journal of Operational Research, vol. 130, no. 3, pp. 498-509, 2001. 


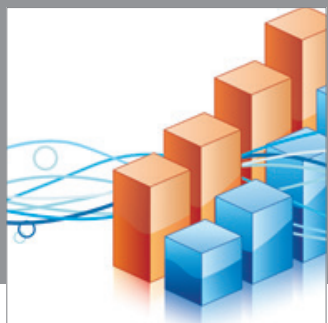

Advances in

Operations Research

mansans

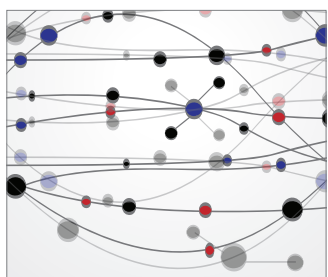

The Scientific World Journal
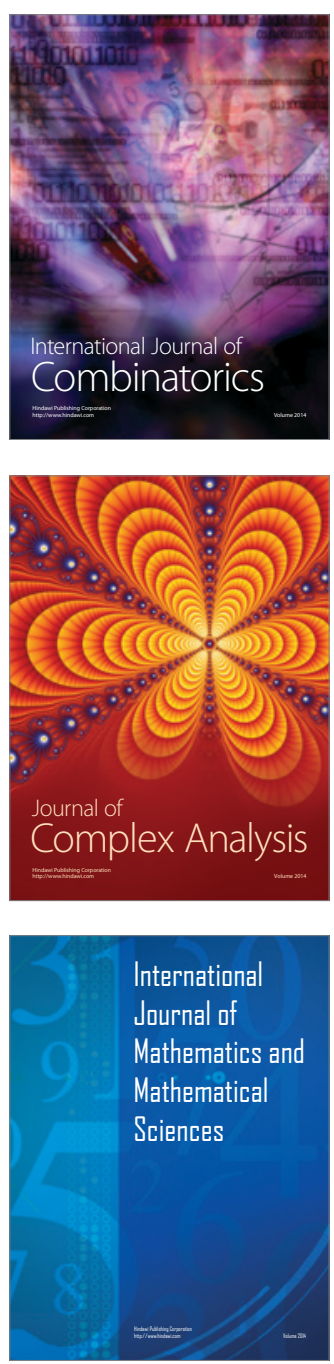
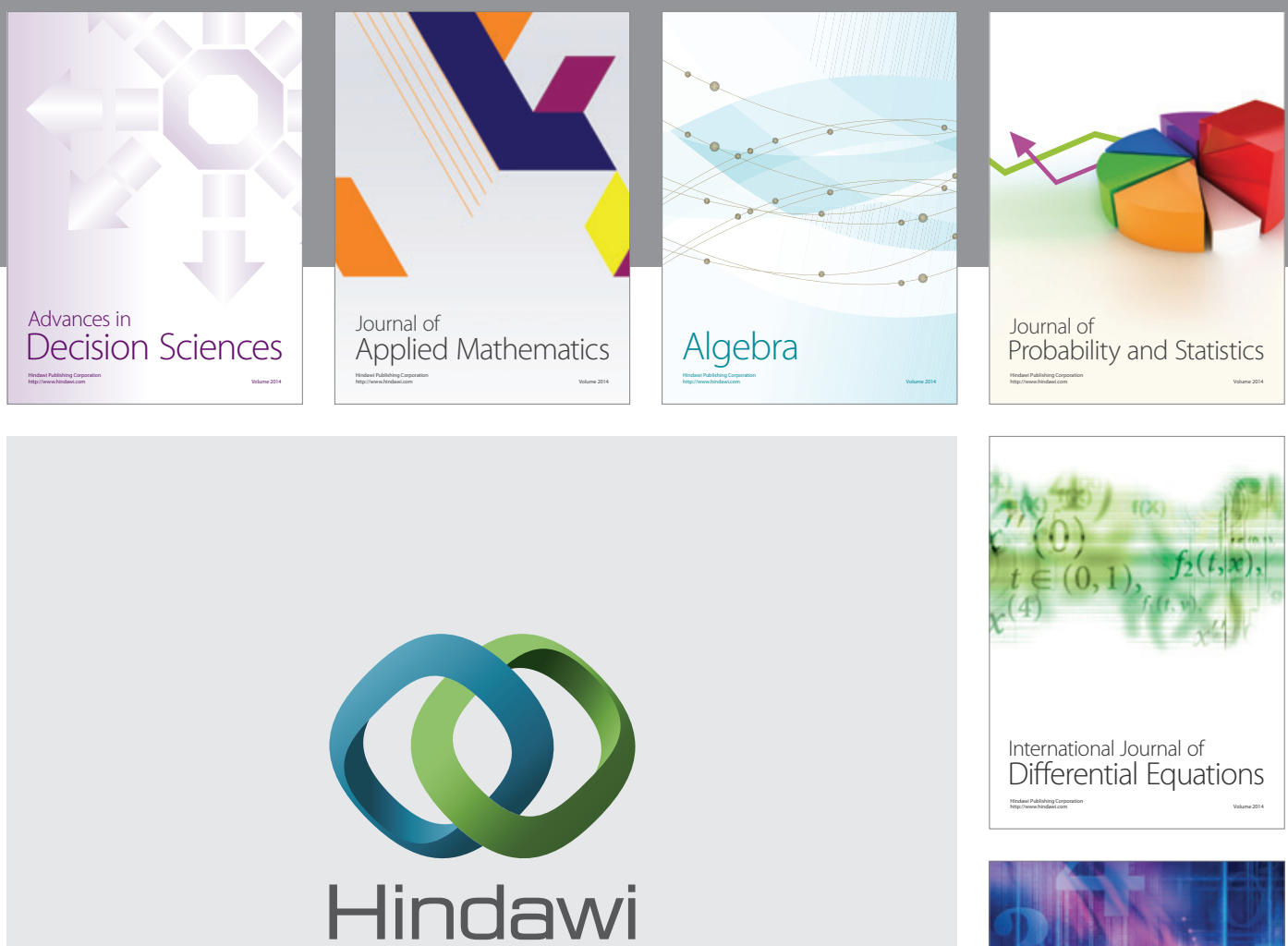

Submit your manuscripts at http://www.hindawi.com
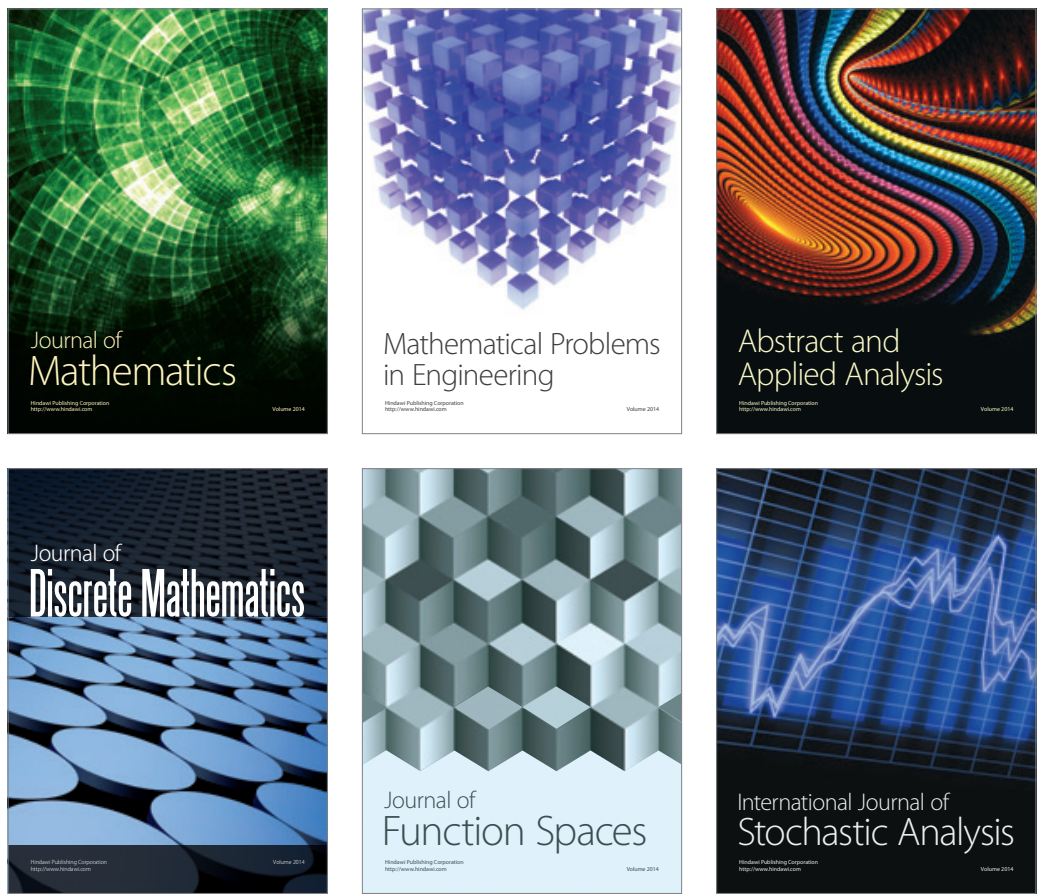

Journal of

Function Spaces

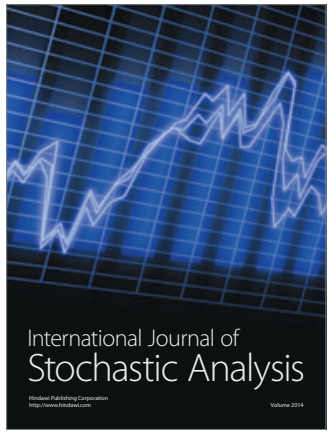

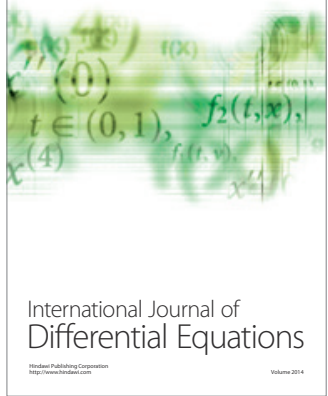
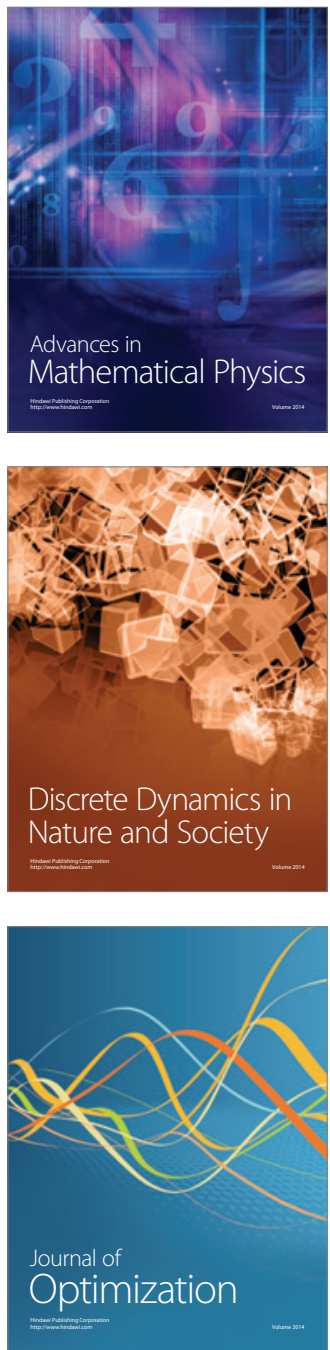